\title{
BULLYING: DIMENSÕES PSICOLÓGICAS NO DESENVOLVIMENTO MORAL
}

LUCIENE REGINA PAULINO TOGNETTA PEDRO ROSÁRIO

\section{RESUMO}

Compreender e avaliar a dimensão que tomam os mecanismos psicológicos atuantes em ações de uma violência específica como o bullying pode contribuir para a discussão das intervenções educacionais que promovam a formação moral desejada pelas instituições de ensino. A pesquisa atual objetivou relacionar tal forma de violência chamada bullying às representações de si e ainda às formas pelas quais os sujeitos se autorregulam em situações hipotéticas que apresentem o problema, constatando assim seus engajamentos ou desengajamentos morais. Os procedimentos realizados para verificar a presença dessas relações apontam que sujeitos cujas representações de si são individualistas também se apresentam mais desengajados moralmente e mais propensos a serem autores em situações de bullying, mostrando assim que mais do que um problema social, as questões de convivência devem ser tratadas do ponto de vista moral.

PALAVRAS-CHAVE BULLYING - QUESTÕES MORAIS - ÉTICA • VIOLÊNCIA NA ESCOLA. 


\section{RESUMEN}

Comprendery evaluar las dimensiones que toman los mecanismos psicológicos actuantes en acciones de violencia específica como el bullying puede contribuir a una discusión sobre intervenciones educativas que promuevan la formación moral deseada por las instituciones de enseñanza. La investigación actual tuvo como objetivo relacionar tal forma de violencia llamada bullying con las representaciones de sí y, también, con las formas por las cuales los sujetos se autorregulan en situaciones hipotéticas que presenten el problema, constatando así su compromiso o falta de compromiso moral. Los procedimientos realizados para verificar la presencia de dichas relaciones señalan que los sujetos cuyas representaciones de sí son individualistas también se muestran menos comprometidos moralmente y más propensos a ser autores de situaciones de bullying, lo que revela que más que un problema social, las cuestiones de convivencia deben ser tratadas desde un punto de vista moral.

PALABRAS CLAVE BULLYING • CUESTIONES MORALES • ÉTICA • VIOLENCIA EN LA ESCUELA.

\footnotetext{
ABSTRACT

Understanding and assessing the extent of psychological mechanisms that operate in actions of specific violence acts such as bullying can contribute to the discussion ofeducational interventions that promote moral education as desired by educational institutions. The current research aimed to correlate this form of violence called bullying to representations of the self and even to the ways in which the subjects self-regulate themselves in hypothetical situations which pose the problem, thus identifying their moral commitments or non-commitments. The procedures followed to check the presence of these correlations indicate that subjects whose self-representations are individualistic are less morally committed and more likely to be perpetrators in bullying situations. This shows that more than a social problem, the issues of coexistence should be treated from a moral perspective.

KEYWORDS BULLYING • MORAL ISSUES • ETHICS • VIOLENCE IN SCHOOL.
} 


\section{INTRODUÇÃO}

Entre os fenômenos da violência humana que vêm chamando a atenção de pesquisadores no mundo inteiro, o bullying tem sido alvo de investigações constantes. As características que o diferenciam de outros tipos de conflitos são, entre outras, o fato de que a violência é escondida aos olhos das autoridades e fundada na repetição. Isso significa que aquele que sofre bullying só gostaria de ter na vida um dia comum, visto que todos os dias experimenta o sabor do desprezo, da diminuição aos olhos dos outros. No ato repetido se encontra uma escolha, ainda que inconsciente, de a quem atacar; no ataque, uma vítima que se vê com menos valor e consente, ainda que de forma inconsciente, no pouco valor que lhe atribuem as ações de seus algozes.

Tanto quem ataca quanto quem sofre o ataque está sob os olhos dos seus iguais, daqueles que participam da constituição de sua identidade, do modo como são e como se veem diante do outro (TOGNETTA, 2012). É exatamente nessa trama de relações constituídas que se busca entender por que agem assim aqueles que submetem os outros e, ao mesmo tempo, 
por que se deixam submeter aqueles que se vitimizam; e, ainda, por que não se indignam aqueles que apenas assistem às cenas de menosprezo que acontecem no seu cotidiano.

Se concordarmos que o ato de menosprezar, diminuir ou agredir, como um substrato de violência, é uma forma de desrespeito, podemos dizer que bullying é um problema moral. E se a moral é uma construção do sujeito, como confirmam os pressupostos interacionistas, podemos nos indagar: que valores são integrados à identidade de sujeitos que agem mal ou agem bem em suas interações com os outros? Que escolhas fazem esses sujeitos para engajarem-se ou desengajarem-se moralmente em uma situação de violência? Essas escolhas explicariam por que meninos e meninas se colocam em situações de bullying? Em uma palavra: existirá uma correspondência entre as representações que os sujeitos têm de si, sua participação em situação de bullying e as formas como se engajam ou desengajam moralmente diante de situações de violência? São exatamente essas perguntas que nos desafiam a apresentar o estudo que agora introduzimos. As respostas, utilizadas no tratamento estatístico dos dados, nos permitirão compreender que a avaliação do fenômeno pode ser conseguida pelas diferentes relações a serem identificadas.

\section{O FENÔMENO BULLYING}

Pretendemos, neste estudo, ampliar as discussões que já existem sobre os mecanismos psicológicos que estão presentes nesses atos de intimidação e menosprezo caracterizados como bullying. Tal fenômeno é entendido como uma subcategoria da violência ou do comportamento considerado agressivo, que se caracteriza pela repetição dessas ações, ou definido como um comportamento por "várias vezes e ao longo do tempo" (OLWEUS, 1999, p. 11). Olweus foi pioneiro nas pesquisas sobre bullying (1993, 1994, 1997, 1999) e suas investigações repercutiram por todo o mundo (SMITH et al., 1999; WHITNEY; SMITH, 1993).

Certamente, mais do que a avaliação psicológica do fenômeno, seu diagnóstico tem levado diferentes governos a instituírem políticas públicas que possibilitem sua intervenção em 
ambientes escolares. Contudo, apenas diagnosticar o problema é, no mínimo, condição insuficiente, tendo em vista a necessidade de compreender o que está por trás dessas ações agressivas que acometem tantos jovens e crianças.

Algumas questões são atualmente enfocadas quando se pensa o problema do bullying, como a influência do corpo docente que, muitas vezes, potencializa o menosprezo com piadas e brincadeiras de mau gosto, como elucidou Lahelma (2002), na Finlândia; Avilés (2006) e Avilés e Alonso (2008), na Espanha; Tognetta e Vinha (2010), no Brasil, entre outros. Há também as diferenças de gênero que apontam características típicas das provocações (BESAG, 2006; NANSEL et al., 2001; OLWEUS, 1993, 1994, 1997, 1999; RINGROSE; RENOLD, 2009; STEIN; DUKES; WARREN, 2006).

Estudos recentes apontam características marcantes para os envolvidos. Jansen et al. (2012) investigaram 6.539 crianças na Holanda e concluíram que fatores de risco como baixa situação econômica e má escola estão associados a maior risco de ser autor e alvo de bullying. Entre os autores de bullying, encontram-se aqueles que são mais populares (TOGNETTA, 2012) e entre as vítimas, aqueles que são geralmente os últimos a ser procurados para os agrupamentos na escola.

Estudos comprovam que autores de bullying estão mais propensos ao uso de drogas, álcool e transtornos psiquiátricos (FEKKES; PIJPERS; VERLOOVE-VANHORICK, 2005) e que têm grandes dificuldades de se adaptar à escola e de obedecer às regras - fato que denota a possibilidade de agirem mal como única alternativa ou legítima resposta para se verem livres de problemas nas relações sociais com os pares (OLWEUS, 1997; BENTLEY; LI, 1995; BOSWORTH; ESPELAGE; SIMON, 1999), haja vista as poucas habilidades sociais que têm (AVILÉS, 2006). São esses que mais precisam ser o centro das atenções, o que talvez seja um modo de esconder o medo de não serem aceitos.

Do ponto de vista daqueles que são alvo de violência, constatam-se também as dificuldades em fazer amigos. Eles apresentam características como a solidão, o sofrimento físico e/ou psicológico, a submissão, a depressão, a ansiedade social 
e uma autoestima negativa (ESLEA et al., 2004; NANSEL et al., 2001; OLWEUS, 1993; SCHWARTZ, 2000). Fisher et al. (2012), numa investigação recente com autorrelatos de 2.141 crianças, encontraram que $2,9 \%$ delas praticavam a automutilação e que mais de metade era vítima de assédio moral frequente.

Trata-se, portanto, como mostram diferentes investigações de um alvo fragilizado que, inconscientemente, como já dissemos, consente o fato de ser menosprezado pelos outros por acreditar que não merece respeito (TOGNETTA, 2012; TOGNETTA; VINHA, 2009; AVILÉS, 2013). Contudo, estudos de Ortega, Del Rey e Mora-Merchán (2001) apontam a dificuldade que temos de reconhecer que o próprio autor de bullying raramente tem consciência da sua intenção de prejudicar outra pessoa. Esse é um dos pontos que torna difícil o consenso na comunidade acadêmica (BANSEL et al. 2009; SMITH, 2004) e nos demanda mais uma indagação: será apenas um problema de consciência que falta a autores de bullying?

Antes, porém, de pensarmos em respostas para tal pergunta, há algo nas investigações atuais a dizer sobre o terceiro personagem dessas manifestações: os espectadores. Thornberg e Jungert (2012) realizaram um estudo com 30 estudantes de 9 a 15 anos de idade e investigaram as razões das decisões das crianças para ajudar ou não ajudar a vítima ao presenciar uma cena de bullying. Concluíram que a decisão de ajudar ou não uma vítima depende de como os espectadores avaliam a situação e sua própria ação na situação em relação aos alvos.

Não seria, então, a falta de uma avaliação moral algo a se considerar quando meninos e meninas se colocam como autores ou não se colocam indignados diante da violência? Não estaria essa mesma violência sendo incorporada como um valor para esses sujeitos? É o que tanto Sánchez, Ortega, e Menesini (2012) como Thornberg e Jungert (2012) apontam como perspectiva para novos estudos. Há os que cumprem essa tarefa percorrendo um caminho que é entender como se engajam ou desengajam os sujeitos em situações de violência, ou seja, o quanto os sujeitos que participam do problema do bullying consideram a violência como um valor positivo ou algo errado. Passemos a incorporar as pesquisas que trazem tais discussões. 


\section{ENGAJAMENTOS E DESENGAJAMENTOS MORAIS}

Obras de Piaget (1932) e Bandura (1999, 2002), embora contempladas por construções teóricas diferentes, do ponto de vista moral, concordam com o papel de "atividade" ou de "agência” (respectivamente) do sujeito para suas escolhas morais. Dessa forma, ambos acreditam que é por um processo de autorregulação (guardadas as peculiaridades de compreensão deste termo em cada uma das teorias) que um sujeito age moralmente e não por simples internalização.

Para Bandura, a autorregulação se caracteriza como uma autorreação de natureza avaliativa às intervenções que o meio impõe: como são observados e compreendidos os acontecimentos externos e como se reagirá no momento atual e futuro. Para Piaget, essa força regulatória viria da vontade: um poder de escolha em agir bem ou agir mal movido por uma hierarquia de valores. Diríamos que é um poder de escolha, um árbitro moral que avalia uma determinada situação, ativando mecanismos que operam no sujeito para que ele possa agir pelo dever moral ou não. Para Piaget, quando operado por reciprocidade e tomado pela comoção ao estado afetivo do outro, o sujeito é movido por culpa, vergonha, arrependimento, indignação e outros tantos sentimentos morais que intervêm para o resgate do dever moral que está em jogo. Quando falta a moral, explicaria Bandura, haveria uma espécie de desinibição ou a "liberação" do sujeito de autocensura ou desses mesmos sentimentos. Age assim, com potencial desapego ao problema do outro. Seria o que o autor chamou de "disinhibitory power of moral disengagement", ou poder desinibitório de desengajamento moral (BANDURA et al., 2001, p. 126).

O mesmo autor revisou uma grande quantidade de pesquisas, demonstrando a presença do que chamou de "desengajamentos morais" e o que seriam, para Piaget, julgamentos heterônomos nos quais o sujeito não consegue se colocar no lugar do outro e se comover com sua dor. Bandura apresenta oito grandes formas de como "pessoas boas podem fazer coisas más" (BANDURA, 1999, 2002). Seriam oito justificativas ou formas de autoproteção e centração em si mesmos que impedem os sujeitos de agirem bem. Oito "poses", portanto, como se as ações cuja moral é ausente pudessem ser fotografadas: 
1) minimizam, ignoram ou distorcem o impacto do prejuízo causado; 2) culpabilizam a vítima pelo dano; 3) consideram uma causa digna de um propósito moral o desatino da víti$\mathrm{ma}$; 4) usam uma linguagem que soa menos negativamente (linguagem eufemística); 5) comparam o problema a outros mais negativos, como sendo uma vantagem da vítima; 6) minimizam e difundem a responsabilidade de quem age mal; 7) transferem ou deslocam tal responsabilidade a uma autoridade; 8) finalmente, apresentam a vítima como merecedora desses atos desumanos (desumanização da vítima).

Assim, estudos como os de Menesini e Camodeca (2008) e de Almeida, Correia e Marinho (2010) apontam para a necessidade de entender como se engajam ou desengajam moralmente os sujeitos a fim de compreender o comportamento agressivo. Menesini et al. (2003) investigaram o grau em que, por exemplo, autores, vítimas e espectadores demonstravam emoções associadas à responsabilidade moral (culpa e vergonha) e desengajamento moral (orgulho, indiferença) entre estudantes da Espanha e da Itália. Seus resultados indicam que as emoções de desengajamento moral estão muito mais próximas dos autores de bullying e mais distantes das vítimas.

Uma pesquisa realizada por Thornberg e Jungert (2012) com 347 adolescentes aponta para uma relação entre menor sensibilidade moral e o autor "valentão" que também apresenta mais desengajamentos morais em suas ações. Wachs (2012) investigou as semelhanças e diferenças entre os papéis de quem participa de bullying tradicional e de cyberbullying, em termos de desengajamento moral, e constatou que entre os 517 estudantes alemães, aqueles que participam de cyberbullying apresentam maior desengajamento moral do que aqueles que o fazem apenas de maneira tradicional. Esse fato denota que, virtualmente, a desinibição pode ser ainda maior. Todavia, outras pesquisas contestam tal fato: Perren e Gutzwiller-Helfenfinger (2012) realizaram uma pesquisa online com estudantes de 12 a 19 anos e encontraram, predominantemente entre aqueles que se autorrelataram participantes desse tipo de agressão, a falta de valores morais e a falta de remorso ou arrependimento para o bullying tradicional e 
para o cyber, porém os desengajamentos morais apareceram muito mais para o bullying tradicional.

Em relação aos espectadores de bullying e desengajamentos morais, Obermann (2011) dividiu 660 adolescentes dinamarqueses em quatro grupos: 1) os que são apenas espectadores; 2) os que são espectadores, mas são propensos a ajudar as vítimas. 3) os espectadores culpados que nada fazem, mas assim se sentem. 4) os indiferentes que tudo testemunham, mas nada sentem. Os resultados foram promissores: os indiferentes tiveram desengajamentos morais significativamente maiores do que os culpados ou defensores.

A mesma autora (OBERMANN, 2011), em outro estudo, investigou se haveria relação entre desengajamento moral e as diferentes posições que assumem as crianças em autorrelatos sobre bullying: quando são nomeadas como valentões ou alvos ou quando se autorreferem dessa forma. Os resultados dessa pesquisa, que envolveu 739 crianças dinamarquesas com 12 anos de idade, demonstraram que tanto as que se autorreferiram como valentões como as que foram assim indicadas apresentaram maior desengajamento moral.

Turner (2009) buscou compreender as relações entre gênero e desengajamentos morais e participação em situações de bullying. Numa amostra com 930 estudantes, constatou que os meninos apresentaram mais desengajamentos morais do que as meninas. Além disso, também constatou que quanto mais desengajamentos morais apresentavam maior participação em bullying tinham esses sujeitos.

Almeida, Correia e Marinho (2010), em uma pesquisa com 292 sujeitos, examinaram como o desengajamento moral, a empatia e as crenças morais sobre os papéis de agressor e defensor da vítima estavam relacionados com as atitudes tomadas por eles. Os resultados apontaram para uma relação entre mais desengajamento moral e mais exercer o papel de valentão; menor desengajamento moral e exercer o papel de defensor da vítima.

Almeida, Correio e Marinho (2010), Obermann (2011), Sagone e Licata (2009) e Turner (2009) destacam a preocupação com outras investigações que possam dar conta de aprofundar dimensões psicológicas relacionadas com a regulação 
interpessoal no contexto escolar. Sagone e Licata (2009), numa amostra de pré-adolescentes, buscaram investigar a relação entre o ajuste interpessoal, o uso de mecanismos de desengajamento moral, assédio moral e comportamentos pró-sociais. Os resultados mostraram haver uma relação entre a impulsividade, menor competência nas habilidades sociais, desengajamento moral e o envolvimento em bullying. Mas há um dado relevante nessa investigação: aqueles que mais participavam de situações de bullying sofrendo as agressões de seus pares eram os mais preocupados com a autoimagem que tinham diante dos outros.

Nesse sentido, não haveria, além da forma como se engajam moralmente ou não nessas situações, uma relação também com as formas pelas quais meninos e meninas se veem? Passemos, então, a mais um aspecto que pode ser avaliado para pensar o problema em questão.

\section{AS REPRESENTAÇÕES DE SI}

Temos insistido no fato de que nossa identidade consiste no conjunto de "representações de si", ou seja, sentimentos, representações, conhecimentos, sonhos e projetos relacionados ao si mesmo, que é definido como "um sistema onde todas as referências pessoais e personalizadas se encontram organizadas" (BARIAUD, 1997). Podemos compreender esse "si mesmo" pela análise de suas referências identificatórias e que, portanto, formam a personalidade.

Dessa forma, quando perguntamos a alguém o que é preciso que se faça para merecer sua admiração, podemos pensar que tratar do que é admirável no outro remeta a uma imagem ideal. Podemos almejar uma imagem ideal enquanto um valor que pretendemos atingir ou que temos na própria escala de valores. O que a faz ser ideal é exatamente o fato de preservar aqueles valores que se tem e que se conserva. Uma duplicidade desse ideal, diríamos, é que pode nos indicar os valores associados a essa identidade.

Diria ainda Smith (1999) que "o amor e admiração que dedicamos àquele cujo caráter e conduta aprovamos predispõem-nos a desejar nos convertermos em objetos dos mesmos sentimentos agradáveis, e a sermos tanto quanto amá- 
veis e admiráveis" (p. 143). Nesse sentido, identificar quais são as representações que sujeitos têm de si permite-nos compreender os valores que estão associados à sua identidade: se são valores individualistas que não consideram o outro; se são valores muitas vezes caracterizados por estereótipos, cuja finalidade é apenas de serem bem vistos aos olhos dos outros, e mesmo que estão apenas associados a pequenas convenções sociais; ou se, realmente, são valores que incluem a si e ao outro como desejantes de um conteúdo moral: se há justiça, generosidade, tolerância sendo destacada como um objeto a ser admirado.

No Brasil, várias investigações têm sido realizadas visando conhecer as representações que diferentes sujeitos têm de si e que tipo de valores estaria integrado em cada uma das formas pelas quais as pessoas se apresentam (TOGNETTA; BOZZA, 2012; TOGNETTA; LA TAILLE, 2008; TOGNETTA; MARCOM; VINHA, 2012). A primeira delas, em 2006, reiterou a correspondência entre representações de si que integram valores éticos e o fato de se sensibilizar com a dor do outro. Numa amostra de 150 adolescentes brasileiros e suíços, observou-se que o reconhecimento do dever moral é sentido por quaisquer pessoas, não importando as representações que elas tenham de si; contudo, reconhecer os sentimentos das pessoas que são acometidas pela injustiça ou pela falta de generosidade é possível muito mais para aqueles cujas imagens se admire ou aspire por esses mesmos valores. Em outra investigação, (TOGNETTA; BOZZA, 2012) pôde-se constatar uma correspondência entre estar envolvido em situações de cyberbullying e representações de si individualistas em que o outro não é considerado. Esses estudos, juntamente com os de Bariaud, na França, trazem a possibilidade de, pelas representações de si, compreendermos as hierarquias de valores que são integradas à identidade de um sujeito.

\section{A PRESENTE INVESTIGAÇÃO: O MÉTODO}

Haveria uma correspondência entre a participação em situações de bullying, as suas representações de si e como se autorregulam para compreender um conteúdo moral em jogo, desengajando-se ou engajando-se moralmente? Para respon- 
der a essa questão investigamos os julgamentos de 2.600 adolescentes, cuja média de idade é de 15 anos, estudantes do $9^{\circ}$ ano do Ensino Fundamental II, advindos de escolas públicas e particulares do Estado de São Paulo. Numa amostra por conveniência, os sujeitos responderam a um questionário com perguntas abertas e fechadas.

De caráter descritivo, a atual pesquisa de campo foi dividida em quatro estudos cujo grande objetivo foi verificar a presença de relação entre dois construtos que podem trazer explicações ao fenômeno bullying: como os sujeitos envolvidos em situações de bullying se veem - suas representações de si e como os sujeitos envolvidos em situações de bullying se autorregulam para a compreensão de uma situação em que um conteúdo moral esteja em jogo - por desengajamentos morais ou engajando-se moralmente. As escolas foram contatadas pelos pesquisadores e foi solicitado o termo de consentimento livre e esclarecido para a participação dos alunos neste estudo. Apresentou-se a carta-convite, descrevendo e assegurando os critérios éticos de acordo com a Universidade do Minho - Portugal, onde a investigação foi organizada em parceria entre grupos de pesquisas brasileiro (Grupo de Estudos e Pesquisas em Educação Moral - GEPEM) e português (Grupo Universitário de Pesquisa em Autorregulação - GUIA).

\section{ESTUDO}

Para constatar se os estudantes já haviam participado de situações de bullying, foram feitas as seguintes perguntas, baseadas nos instrumentos desenvolvidos por Avilés (2013):

1- Assinale uma das alternativas para responder à pergunta: você já foi agredido, maltratado, humilhado na frente dos outros, ameaçado ou caçoado por algum(a) colega na escola? Com que frequência isso aconteceu ou tem acontecido neste ano?

2- Assinale uma das alternativas para responder à pergunta: você já intimidou, tirou sarro de alguém para irritá-lo, maltratou, humilhou ou ameaçou algum colega? Com que frequência isso aconteceu ou tem acontecido no ano? 
3- Assinale uma das alternativas para responder à pergunta: você já viu alguém que é ou que tenha sido insultado, agredido, ameaçado, maltratado, intimidado, caçoado com apelidos pejorativos em sua escola? Com que frequência você presenciou essas cenas no ano?

Aos três itens formulados, as alternativas dadas eram: não, nunca; sim, uma única vez isso aconteceu; sim, uma ou duas vezes por semana aconteceu ou tem acontecido; sim, mais de duas vezes na semana aconteceu ou tem acontecido; ou, finalmente, sim, todos os dias tem acontecido.

\section{2 ㅗSTUDO}

Utilizando-se o instrumento validado por Tognetta e La Taille (2008) para reconhecer as representações que os sujeitos têm de si, perguntamos aos sujeitos: o que uma pessoa faz que você admira e o que as pessoas podem admirar em você?

\section{3 ㅗTUUDO}

Para conhecer as formas pelas quais os sujeitos se engajam ou desengajam diante de uma situação de bullying, utilizamos um instrumento composto por duas histórias: na primeira delas, o personagem principal era alvo constante de bullying dos colegas que o ameaçavam, agrediam verbalmente, mas ele não reagia. Nessa história, havia uma consequência material da intimidação: os agressores o faziam pagar refrigerantes. Na segunda história, as intimidações e agressões eram a uma vítima considerada "provocadora” por suas reações bruscas e constantes ataques aos demais. A consequência desses atos, nesse caso, não era material, e sim a exclusão do grupo. Para cada história foram formuladas 14 alternativas. Dentre elas, oito correspondiam exatamente às oito formas de desengajamento moral propostas por Bandura (1999, 2002), descritas por nós anteriormente. Como exemplos, temos para a primeira história as seguintes alternativas: "Ele mesmo (Japinha) se excluía do grupo de meninos" ou "Se todo mundo zoa com ele, por que os outros também não podem aproveitar e tomar a coca-cola?" e ainda: "Os colegas agiam assim porque seguiam a ordem de Jorge. Ele é que 
comandava as brincadeiras”. Na história de Joana, temos as seguintes alternativas como exemplos de desengajamentos morais: "Carol e as meninas não gostam do fato de Thereza querer ser o centro das atenções e também de Thereza atrapalhar o grupo por não ter habilidades esportivas" ou "Isso é só brincadeira, não vale a pena ficar tão preocupado”. Ou ainda "Todo mundo sabe que Thereza se comporta diferente das outras meninas, então não é só o grupo de Carol que zoa, todo mundo faz isso".

As demais respostas implicavam numa decisão pelo engajamento moral, ou seja, nessas alternativas os sujeitos reconheciam o desrespeito e a falta de ética nas provocações realizadas com os personagens das histórias. Na história de "Japinha”, são exemplos: "Ninguém pode passar por isso. O que esses meninos fazem com japinha é um desrespeito"; ou "É mais errado o que Jorge fez com Japinha. Chega a ser desumano". E na história de Thereza, os exemplos são: "Não deveria ter xingamentos na escola e em nenhum lugar" ou "Cada um tem o direito de ser como quer e o mais importante é tratar bem as pessoas".

Quanto à validação do instrumento, com a aplicação de análise fatorial pelo método de extração por componentes principais - pela rotação varimax - vimos os agrupamentos que as alternativas assinaladas pelos sujeitos construíram num certo domínio. Com a análise fatorial realizada, constatamos a pertinência desses fatores criados. Pudemos notar que as alternativas se encontraram em dois domínios: os engajamentos morais e os desengajamentos morais. Pela medida KMO, vimos que o modelo formado era adequado $(0,818)$; e aplicando o teste de Bartlett, constatamos também que tais diferenças eram significativas $(p<0,001)$ entre os domínios.

Tínhamos 14 itens no instrumento em cada uma das histórias, sendo que deles 13 itens explicavam o construto “desengaja ou engaja”. Com a análise fatorial, para compor cada domínio, o peso de cada componente precisava ser maior ou igual a 0,40 . Para confirmar a consistência interna do instrumento total nos dois domínios, foi aplicada a medida estatística Alfa de Cronbach. Valores acima de 0,60 indicaram a consistência. Não houve nenhum item que, se 
excluído, aumentasse a consistência interna. Todos os itens assim foram bem interpretados. Validado o instrumento utilizado, apresentaremos as formas de desengajamento mais utilizadas por nossos sujeitos nos resultados do $3^{\circ}$ estudo.

\section{4으 ESTUDO}

O quarto estudo trata da verificação de existência de relação entre os três estudos anteriores. Passemos, então, à apresentação dos resultados.

\section{RESULTADOS}

\section{ESTUDO}

Para analisar as respostas dadas às três perguntas realizadas em nosso instrumento sobre a participação em situações de vitimização foi preciso criar um critério que correspondesse às possíveis indicações de que haveria, de fato, uma situação de bullying. Assim, as alternativas criadas foram divididas em categorias para serem analisadas: "autor total"; "vítima total" e "espectador total" correspondem a quando há a indicação da repetição das ações (mais de uma vez) - citados a partir daqui como "1"; e quando não há a repetição como "0".

Dessa forma, quando questionados sobre o envolvimento em situações de vitimização, menosprezo, humilhação ou agressão entre pares, foi possível constatar que 15,9\% dos participantes dessa investigação já foram vitimizados. Dos estudantes, 19,5\% disseram também já ter intimidado, menosprezado ou agredido seus pares repetidamente e $62,8 \%$ já foram espectadores desse tipo de violência. A Tabela 1 apresenta tais resultados.

TABELA 1 - Vitimização entre escolares

\begin{tabular}{l|c|c|c}
\hline PARTICIPANTE & ESCOLA PARTICULAR & ESCOLA PÚBLICA & TOTAL \\
\hline Vitima & $14,4 \%$ & $17,2 \%$ & $15,9 \%$ \\
\hline Autor & $17,7 \%$ & $21,0 \%$ & $19,5 \%$ \\
\hline Espectador & $63,2 \%$ & $62,4 \%$ & $62,8 \%$ \\
\hline
\end{tabular}

Fonte: Dados da pesquisa. 
Como explicar as características que tomam esses participantes do bullying? Haveria relações com as imagens que esses meninos e meninas têm de si? Estariam eles engajados ou desengajados moralmente para assim se apresentarem envolvidos nessas situações de violência? Tais perguntas, objeto de nossa investigação, serão respondidas. Contudo, é preciso antes apresentar os dados dos dois estudos seguintes que nos trazem as indicações de como são as representações de si desses mesmos sujeitos e como se engajam ou desengajam moralmente para então proceder à verificação da existência de relações.

\section{2을 ESTUDO}

As respostas encontradas para as duas perguntas "O que uma pessoa faz que mereça sua admiração?" e "O que as pessoas podem admirar em você" foram organizadas a partir das categorias formuladas por Tognetta e La Taille (2008) e consistiam basicamente em três: na primeira, encontram-se as repostas que trazem conteúdos individualistas, ou seja, em que os sujeitos não fazem menção a nenhum valor moral e sim a conteúdos do tipo "meus cabelos" ou "admiro um sujeito que jogue bem futebol”. Portanto, nessas respostas, o "outro" não é incluído e nem está em jogo um conteúdo moral. Na segunda categoria, as respostas já apresentam conteúdos morais, porém, ainda estereotipados ou ligados a relações próximas como: "admiro a beleza e a inteligência das pessoas" ou ainda "admiro a simpatia e a bondade da minha mãe”. Nessas respostas, não fica clara a intenção de incluir o sujeito universal como acontece nas da terceira categoria, nas quais se encontram conteúdos éticos, já que tanto contêm valores morais - como a generosidade, a honestidade - como apresentam um "outro generalizado", como, por exemplo: "É preciso que seja bem honesto e que saiba respeitar as pessoas do jeito que elas são". Com base em tais análises, o método consistiu em encontrar uma categoria em que as duas respostas dadas pelos sujeitos fossem conservadas na mesma categoria, de modo a termos as possibilidades descritas no Quadro 1. 


QUADRO 1 - Categorias para as representações de si
\begin{tabular}{|l|c|}
\hline CATEGORIA & \\
\hline CA & DESCRIÇÃo \\
\hline CB & Respostas que conservam em A, com conteúdos individualistas. \\
\hline CC & Respostas que conservam em C, com conteúdos de caráter moral. \\
\hline NC & Respostas que não conservam a mesma categoria nas duas perguntas sobre admiração. \\
\hline
\end{tabular}

Fonte: Dados da pesquisa.

Obteve-se como resultados que somente $8,8 \%$ das respostas apresentadas correspondem a conteúdos éticos. Chama-nos a atenção o fato de que $17,9 \%$ das respostas são de caráter individualista e 33,9\% dos sujeitos não conservam a mesma categoria nas duas respostas sobre o valor a ser admirado. Das respostas dos sujeitos, 39,4\% pertencem à categoria dos estereótipos sociais.

\section{ESTUDO}

Como se autorregulam esses sujeitos para responder a situações em que haja um conteúdo moral em jogo - engajam-se ou se desengajam moralmente? Para responder a essa questão, elaboramos um instrumento que pudesse mensurar os desengajamentos e engajamentos morais para uma situação em que o conteúdo de violência como bullying estivesse presente. Esse instrumento, conforme vimos, foi validado.

Na primeira história, havia uma situação de menosprezo em que a agressão se remetia a uma consequência material: o sujeito agredido deveria pagar refrigerantes aos outros meninos. Notou-se que $29,1 \%$ dos sujeitos acreditam que havia alguém no comando e, portanto, quem agiu mal só obedeceu (descolamento de responsabilidade). Ao mesmo tempo, 16,5\% comparam a ação agressiva à outra que poderia ser bem pior: não houve agressão física, o que faz com que essa ação de menosprezo e de intimidação seja considerada menos grave. É interessante notar que 13,6\% dos respondentes assinalaram a alternativa cuja explicação para não se engajar moralmente foi a desumanização, e 13,5\% culpabilizaram a vítima. 
Passemos para o caso 2, em que a situação de bullying acontece com uma vítima de certa forma provocadora. Vejamos as formas de desengajamento mais comuns encontradas entre nossos sujeitos.

Da mesma forma que no caso anterior, os sujeitos respondentes acreditam que a responsabilidade é sempre de outros e não sua (29,7\%). Chama-nos a atenção, nesse caso, a difusão da responsabilidade: se todo mundo faz isso, não é tão ruim (28,1\%). E ainda, 27,4 foram respostas cuja atribuição de culpa é feita à própria vítima. Já 23,7\% justificaram seu não engajamento negando as características humanas da vítima.

A pergunta que se faz agora é: quem seriam aqueles que mais apresentam as formas de desengajamento moral? Quais seriam as representações de si desses sujeitos? Que relações podem contribuir para explicar as características dessa forma de violência, o bullying, que acomete jovens e crianças? Passemos, então, às relações que encontramos entre esses três construtos: a participação em situações de bullying, as representações que esses sujeitos têm de si e sua forma de engajar-se ou desengajar-se moralmente.

\section{REPRESENTAÇÕES DE SI E PARTICIPAÇÃO}

NA VITIMIZAÇÃO

Quando examinamos as relações entre as representações de si ao fato de os sujeitos serem vítimas totais ou espectadores totais nas situações de bullying, não encontramos diferenças significativas $(p>0,79$ para vítimas e $p>0,74$ para espectadores). Isso significa que tanto vítimas como espectadores de bullying podem se apresentar com imagens de si individualistas, estereotipadas ou com valores éticos. Ou, dito de outra forma, para ser espectador ou vítima de bullying, não importa que tipo de representações os sujeitos possam ter de si. Contudo, é na comparação das distribuições de frequência quanto à autoria de bullying por categoria de representação de si que encontramos diferenças estatisticamente significantes $(p<0,01)$, como podemos constatar na Tabela 2 . 
TABELA 2 - Representações de si e autoria de bullying

\begin{tabular}{|c|c|c|c|c|c|c|c|c|c|c|}
\hline \multirow{3}{*}{$\begin{array}{l}\text { REPRESENTAÇÃO } \\
\text { DE SI } \\
\\
\text { CATEGORIA }\end{array}$} & & \multicolumn{9}{|c|}{ AUTORIA DE BULLYING* } \\
\hline & \multicolumn{3}{|c|}{ NÚMERO DE RESPONDENTES } & \multicolumn{3}{|c|}{$\begin{array}{c}\text { PORCENTAGEM } \\
\text { SEGUNDO A CATEGORIA }\end{array}$} & \multicolumn{3}{|c|}{$\begin{array}{c}\text { PORCENTAGEM } \\
\text { SEGUNDO A AUTORIA }\end{array}$} & \multirow[b]{2}{*}{ TOTAL } \\
\hline & DESCRIÇÃO & 0 & 1 & TOTAL & 0 & 1 & TOTAL & 0 & 1 & \\
\hline CA & $\begin{array}{l}\text { Conservam em A, } \\
\text { com conteúdos } \\
\text { individualistas. }\end{array}$ & 317 & 123 & 440 & 72,0 & 28,0 & 100,0 & 15,9 & 26,3 & 17,9 \\
\hline CB & $\begin{array}{l}\text { Conservam em B, } \\
\text { com conteúdos } \\
\text { de caráter } \\
\text { estereotipado. }\end{array}$ & 811 & 159 & 970 & 83,6 & 16,4 & 100,0 & 40,7 & 34,0 & 39,4 \\
\hline CC & $\begin{array}{l}\text { Conservam em C, } \\
\text { com conteúdos de } \\
\text { caráter moral. }\end{array}$ & 190 & 28 & 218 & 87,2 & 12,8 & 100,0 & 9,5 & 6,0 & 8,9 \\
\hline NC & $\begin{array}{l}\text { Não conservam a } \\
\text { mesma categoria } \\
\text { nas duas perguntas } \\
\text { sobre admiração }\end{array}$ & 676 & 158 & 834 & 81,1 & 18,9 & 100,0 & 33,9 & 33,8 & 33,9 \\
\hline TOTAL & & 1994 & 468 & 2462 & 81,0 & 19,0 & 100,0 & 100,0 & 100,0 & 100,0 \\
\hline
\end{tabular}

(*) Autor em mais de uma situação (1).

Fonte: Dados da pesquisa.

Pela Tabela 2, constata-se que a distribuição dos autores de bullying (1) e dos demais (0) frente às categorias de representação de si apresenta uma diferença relevante. Enquanto 26,3\% dos autores (1) mantêm suas representações de si conservadas em respostas de conteúdo individualista, no outro grupo (0), apenas $15,9 \%$ o fazem.

\section{VITIMIZAÇÃO E AUTORREGULAÇÃO MORAL}

Quando relacionamos a participação em situações de vitimização do alvo de bullying (vítima total) com suas formas de engajar-se ou desengajar-se moralmente, constatamos que não há diferenças significativas $(p=0,88)$. Tanto podem ser engajadas (fator 1) como desengajadas (fator 2). Contudo, o espectador de bullying é mais engajado (a média é positiva) e isso é significativo ( $p<0,01)$, porém não é menos desengajado $(p>0,72)$. 
Chama-nos a atenção, porém, o fato de que o autor de bullying é mais desengajado (sua média é positiva para o desengajamento) e menos engajado (a média é negativa para o engajamento) e essa diferença é significativa para os dois - engajamento $(p<0,02)$ e desengajamento $(p<0,01)$ em comparação com aqueles que não são autores de bullying (média positiva para o engajamento e negativa para o desengajamento).

\section{REPRESENTAÇÕES DE SI E ENGAJAMENTO/ \\ DESENGAJAMENTO MORAL}

O último procedimento aplicado para verificar relações entre os dados entre o construto "engajamentos e desengajamentos morais" e "representações de si". Utilizando a medida de engajamento e desengajamento, obtida pela análise fatorial (cada questão que cosmpõe o domínio, multiplicada pelas cargas fatoriais), tem-se um número que é mais positivo possível: quanto mais positivo maior é o engajamento ou o desengajamento. Quanto mais negativo, menos engajado e menos desengajado. Assim, obtivemos os resultados apresentados na Tabela 3, considerando Fator 1 - engajamento - e Fator 2 - desengajamentos.

TABELA 3 - Representações de si, engajamento e desengajamento moral

\begin{tabular}{l:l:l} 
& FATOR 1 & FATOR 2 \\
& ENGAJAMENTO & DESENGAJAMENTO \\
\hline CA & -2213480 & 3423898 \\
& 153 & 153 \\
\hline CB & 1627702 & -1299678 \\
& 420 & 420 \\
\hline CC & 1975642 & -3835212 \\
& 74 & 74 \\
\hline NC & -0775581 & 0720215 \\
& 334 & 334 \\
\hline
\end{tabular}

Fonte: Dados da pesquisa.

Observa-se, na Tabela 3, que os CAs (representações de si individualistas) são mais desengajados moralmente $(0,34)$ e menos engajados $(-0,22)$. Nota-se também que os CCs (representações de si éticas) são mais engajados $(0,19)$ e menos desengajados $(-0,38)$. 
Para comparar se essas médias são diferentes entre as categorias de representações de si, foram realizadas análises com a ANOVA, seguidas do teste de Tukey para a localização das diferenças. Pela ANOVA, foi possível comprovar a diferença significativa para os dois componentes $(p<0,001)$. Para localizar as diferenças - em quais representações de si estariam essas diferenças -, foi aplicado o teste post hoc de Tukey que comprovou que quanto aos engajamentos morais, os CAs ou aqueles cujas representações de si são individualistas são exatamente diferentes daqueles que são CBs (cujas representações de si são estereotipadas), mas não são diferentes significativamente das respostas daqueles que não conservam a mesma categoria de admiração (os NCs). Para melhor visualizar essas informações, vejamos a Figura 1 que trata dos engajamentos.

FIGURA 1 - Escore do engajamento para as representações de si

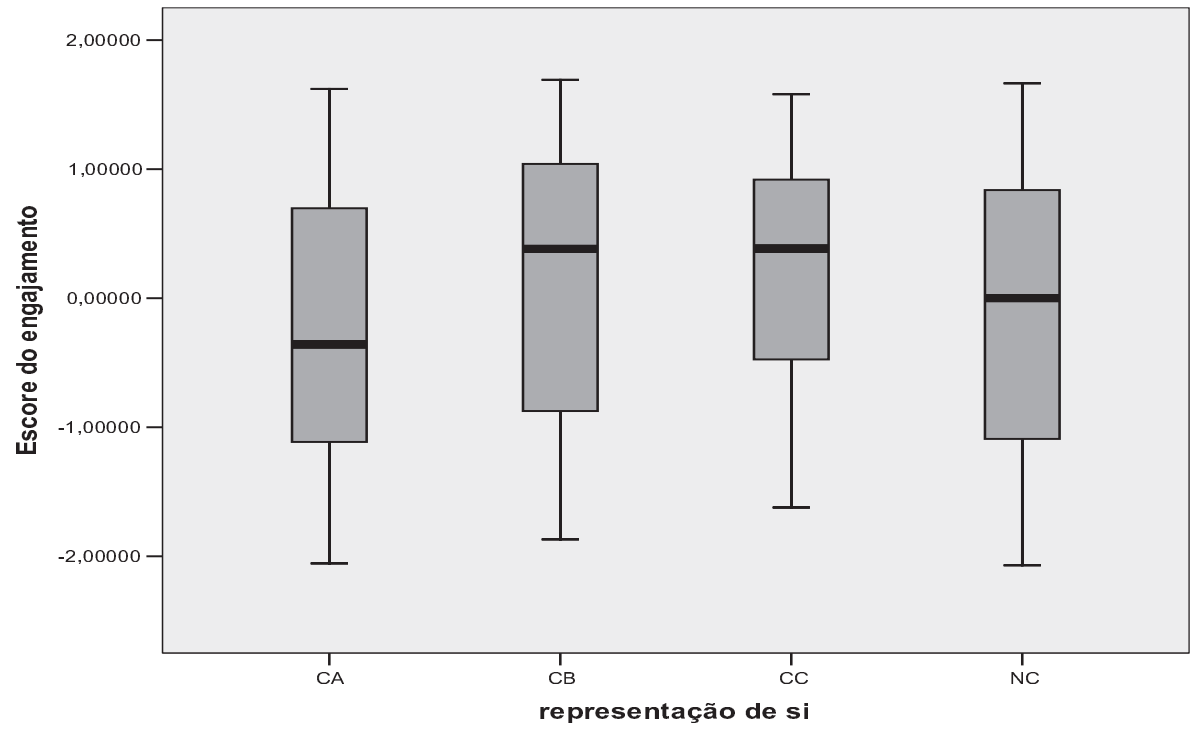

Fonte: Dados da pesquisa.

Observando a Figura 1, podemos constatar que os sujeitos cujas representações de si incluem valores éticos (CCs) possuem menos variabilidade no escore do engajamento; ou seja, são mais consistentes no grupo de respostas que mostram que se engajam moralmente. Além disso, vemos que se mantêm 
acima de 0,00 , o que significa mais engajamento (mais positivo, mais engajado).

Note-se que naqueles cujos estereótipos sociais são mais admirados (os CBs), a variabilidade é bem maior, demonstrando menos consistência na escolha das respostas mais engajadas. Aqueles que não conservam um valor admirado, os NCs, estão também abaixo de 0,00 , o que significa que são menos engajados e, além disso, têm a maior variabilidade. Os CAs são diferentes do CCs e CBs e iguais aos NCs. Com o teste estatístico, os CAs são igualmente menos engajados como aqueles que não conservam um valor (NCs).

E quanto aos desengajamentos? Com a aplicação do teste post hoc de Tukey, obteve-se que os CAs, ou aqueles cujas representações de si são individualistas, são diferentes dos CBs - com conteúdos estereotipados: os CAs são mais desengajados $(0,342)$ que os CBs $(-0,13)$. Na Figura 2 , é possível constatar tais resultados.

FIGURA 2 - Escore do desengajamento para as representações de si

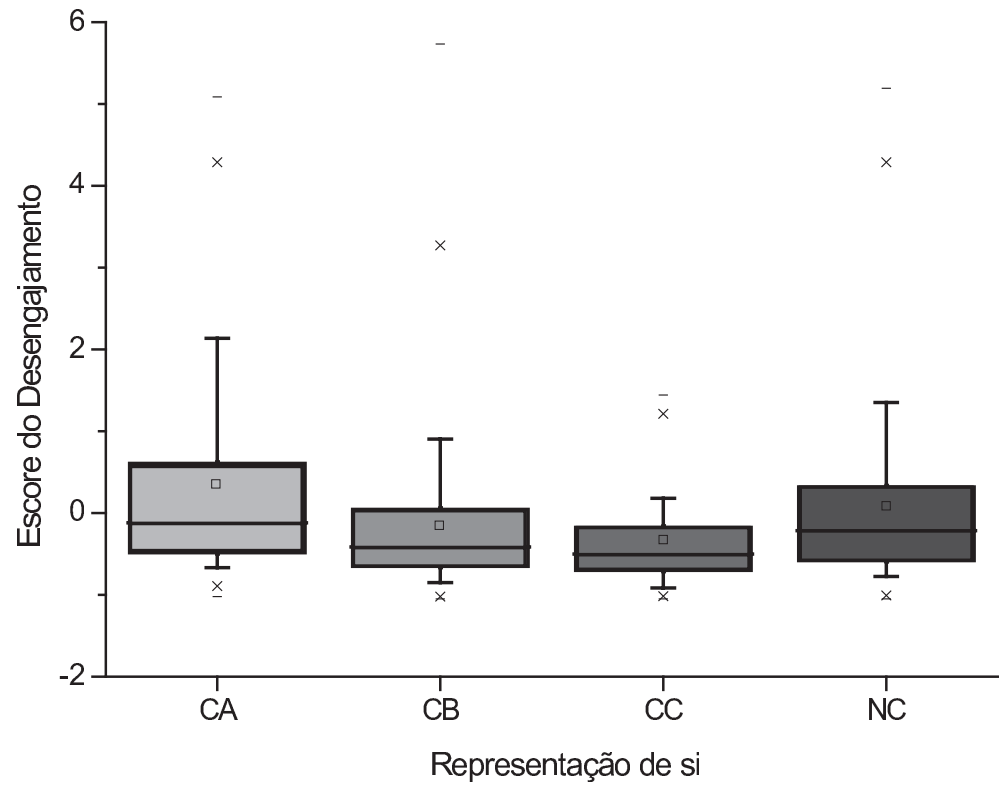

Fonte: Dados da pesquisa 
Como se pode constatar, os CAs são diferentes de todos (ainda que mais próximos dos NCs). A variabilidade dos desengajamentos em seu interior é também maior entre os CAs. São mais desengajados (mais positivo), enquanto os CCs, cujas representações de si são éticas, são menos desengajados (negativo).

\section{DISCUSSÃO}

Os dados encontrados no presente estudo sobre o envolvimento em situações de bullying estão de acordo com a maioria dos diagnósticos feitos na atualidade em todo o mundo: em média $16 \%$ de meninos e meninas são agredidos, expostos a humilhações diante de um grupo que não se indigna e que, consequentemente, reitera que a violência cometida pelos valentões é um valor. No entanto, mais do que diagnosticar, nosso intuito é compreender, pela avaliação sistemática das relações existentes entre os construtos psicológicos que podem incidir sobre o problema, seu funcionamento psicológico. Certamente, diferentes pesquisadores como Sánchez, Ortega e Menesini (2012) já alertaram sobre a necessidade de aprofundar a dimensão emocional e moral dos implicados para conhecer a gênese e a evolução desse fenômeno. É exatamente esse o papel das relações encontradas que pretendemos mostrar neste estudo.

Pudemos constatar que os dois construtos - representações de si e os engajamentos e desengajamentos morais podem explicar as dimensões afetivas e morais que estão em jogo quando os sujeitos se relacionam com outros. Primeiramente, sob a ótica das representações de si, os resultados demonstram que os conteúdos morais pouco são integrados à identidade dos estudantes pesquisados. Somente $8,8 \%$ de nossos sujeitos se referem à admiração a valores morais que incluam a si e ao outro, enquanto $17,9 \%$ se referem a conteúdos individualistas em que não se levam em consideração valores altruístas. Vimos que $39,4 \%$ dos participantes de nossa pesquisa conservam suas respostas na categoria $C B$, dos estereótipos sociais. Kohlberg (1989) poderia justificar tais dados quando alertou, na década de 1980, que dois terços 
da humanidade permaneceriam em estágios intermediários de desenvolvimento moral. Além disso, quando sujeitos não conservam o mesmo valor admirado em suas representações de si tem-se outro problema, já que, como diria Piaget (1932), a moral é a conservação de valores, ou seja, esses sujeitos estão muito mais propensos aos desengajamentos morais.

Ao relacionarmos as representações de si com o envolvimento no fenômeno bullying, observamos que os autores dessa prática de violência apresentam mais representações de si individualistas. Falta-lhes, portanto, o que chamamos de "sensibilidade moral” (TOGNETTA, 2012; TOGNETTA; VINHA, 2010), ou seja, são sujeitos que não incluem o outro em seu universo de valores e não conseguem sair de seu próprio ponto de vista. Tal dado comprova que o bullying é um problema moral ou exatamente de sua falta. Esses resultados corroboram os encontrados por Sánchez, Ortega e Menesini (2012), nos quais crianças agressoras fazem mais uso de desengajamentos morais, e ainda com Obermann (2011), na Dinamarca, que também encontrou uma correlação entre os autores de bullying e os desengajamentos morais.

Em relação aos alvos, nossos resultados apontam que tanto podem ser individualistas, como admirar conteúdos éticos, porque o que lhes falta está relacionado à imagem que têm de si diante do outro; eles se sentem inferiores ao que acreditam ser a determinação das qualidades do grupo ao qual pertencem, conforme alertou Olweus (1997). Chamou-nos a atenção o fato de se encontrar, entre aqueles que se distinguem como alvos em situações de bullying, formas de desengajamento moral que se destacam: a atribuição de culpa e a desumanização como justificativas para o fato de confirmar a violência como um valor.

Não encontramos diferenças significativas entre os autores, alvos e espectadores de bullying, o que significa que ainda que sofram a violência de seus pares, quando analisam uma situação em que há essa mesma forma de maltrato, as vítimas de bullying justificam tais ações culpabilizando quem sofre e emitindo certo desprezo por essa figura. Tais resultados não nos causam nenhum estranhamento, visto que é exatamente assim que a vítima se vê para perpetuar a sua 
situação de vitimização (a saída da condição de vítima pode acontecer já que temos insistido nos "estados" de vitimização (TOGNETTA, 2012; TOGNETTA; VINHA, 2010) por processos inconscientes, como merecedora de tais menosprezos (AVILÉS, 2013; TOGNETTA, 2012).

Contudo, os alvos de bullying se apresentam tanto engajados como desengajados moralmente, o que não acontece quando correlacionamos os autores de bullying aos desengajamentos morais. Eles são mais desengajados e menos engajados nas situações morais. Isso denota, novamente, que a vitimização é um problema moral. Meninos e meninas que são autores de bullying demonstram mais desativar seletivamente o controle de um mau comportamento moral e reconstroem assim o significado dessa conduta reprovável, justificando-a moralmente. Como lembram Sánchez, Ortega e Menesini (2012), as formas de desengajamento moral desinibem tais condutas que seriam moralmente incorretas, pois assim as pessoas se veem liberadas de autocensura e de culpa, o que é típico das situações de heteronomia.

Constata-se outra correlação interessante entre esses dados: desengajamentos morais e representações de si. Aqueles que admiram conteúdos individualistas apresentam diferenças significativas em relação àqueles que admiram conteúdos éticos, mas não são significativamente diferentes em relação àqueles que não conservam uma mesma forma de admiração em suas representações de si. Dessa forma, mostram-se desengajados moralmente, portanto, tanto os individualistas quanto aqueles que não conservam um valor.

Parece-nos relevante também ressaltar, no escore do engajamento moral (Figura 1), a maior variabilidade de respostas quanto ao engajamento dadas pelos CAs, cujas representações são individualistas, e pelos NCs, aqueles que não conservam um valor em comparação com aqueles cujas representações são éticas; e ainda o fato de estes últimos serem mais engajados (mais positivo), não variando tanto as respostas dadas. O mesmo acontece com os desengajamentos; como se observa na Figura 2, os CAs (conteúdos individualistas em suas representações de si) são mais desengajados que os CBs (conteúdos estereotipados), e os CCs (conteúdos 
éticos) praticamente se igualam aos NCs (aqueles não conservam uma mesma categoria de respostas quanto ao que admiram). Novamente, a variabilidade do conteúdo das respostas daqueles cujos valores são éticos permanece menor.

Pornari e Wood (2010), num estudo com 339 crianças do ensino secundário, relacionando o desengajamento moral à agressão tradicional e virtual, constataram como formas de desengajamento moral mais utilizadas: a justificativa moral, a linguagem eufemística e o deslocamento de responsabilidade. Basicamente, seus dados são parecidos com os nossos, porém, destacamos uma resposta bastante encontrada entre nossos sujeitos para a segunda história: a desumanização. Nela, a garota que sofria bullying, na narrativa da história, atrapalhava as aulas e chorava muito quando participava de alguma situação de conflito. Meninos e meninas participantes desse estudo demonstram que não conseguem perceber o sofrimento da vítima por trás de suas ações e, assim, atribuem a culpa a ela própria, acreditando que é, de fato, merecedora do que lhe é predestinado.

Em uma palavra, todos esses elementos somados podem comprovar que o posicionamento moral ante um conflito pode explicar as formas como se atua numa situação de violência. Depois de associarmos os dois construtos à participação em formas de violência como o bullying, podemos afirmar seguramente que o problema da vitimização entre pares precisa ser visto como um problema que envolve a falta de ética, e que, para superá-lo, é preciso considerar que a moral (ou a ética) é uma construção do sujeito que age.

\section{LIMITAÇÕES E IMPLICAÇÕES EDUCACIONAIS}

Num contexto educativo, por mais que se deseje que os estudantes sejam cidadãos éticos, a presença de bullying supõe, para a instituição que educa, um indicador de que tal objetivo não está sendo atingido. Isso certamente acontece porque entre os membros da comunidade escolar haverá aqueles para quem a violência é um valor.

Sabemos que em inúmeras instituições de ensino, principalmente no cenário brasileiro, como vimos numa recente 
investigação com os diretores de escola (TOGNETTA; VINHA, 2013), poucos são aqueles que reconhecem o problema instaurado em suas relações. Poucos são aqueles que se preocupam com uma questão que é imprescindível para quem deseja formar pessoas melhores: a convivência na escola, que tem sido o "calcanhar de Aquiles" de muitas instituições, não somente pela presença do bullying escolar, mas, sobretudo, por tantas microviolências escondidas em seu interior que desafiam educadores a levar em consideração algo que já fora pensado desde há muito tempo no que concerne à educação moral dos jovens e crianças.

Em 1932, Piaget defendia que a cooperação é a única forma de superação da heteronomia vigente. Entretanto, o conceito de cooperação precisa ser bem entendido na perspectiva do epistemólogo suíço: cooperação significa "operar com” e, portanto, tornar o sujeito um agente de seu próprio desenvolvimento, dando-lhe oportunidades de pensar, de antecipar as consequências de seus atos, numa relação de confiança com aqueles que educam. Diz respeito, portanto, à necessidade de criar espaços para que meninos e meninas possam falar de seus problemas, possam pensar nas próprias soluções de seus problemas, possam aprender a reparar seus erros com quem de direito e não com punições enfadonhas que permitem ao sujeito estar livre somente depois de cumprido seu castigo, para novamente cometer outro delito.

Temos insistido, como nas pesquisas de autores espanhóis (AVILÉS, 2006; ORTEGA; DEL REY; MORA-MERCHÁN, 2001; entre outros) em cujo país há políticas públicas que apoiam essa iniciativa, em que as alternativas para vencer o bullying são aquelas que colocam os alunos como protagonistas - ou como agentes, como diria Bandura (2002) -, em que os alunos sejam a solução e não o problema - como lembraria Avilés (2013).

Em uma palavra, se o bullying é um problema basicamente grupal, não seria o grupo o espaço legítimo ao qual se deve voltar para a discussão de como se sentem as pessoas envolvidas, de como se devem tratar as pessoas, de como se gostaria de ser tratado pelos outros? Não seria essa uma forma adequada de educar moralmente?

E se, como vimos, falta a meninos e meninas autores de bullying a sensibilidade moral, é preciso dar a eles a 
oportunidade de constatar os sentimentos daqueles que sofrem. O que acontece é que, muitas vezes, em seu repertório de aprendizagens não conheceram outras formas de relacionamento senão a agressão, a submissão e o menosprezo (HOOVER; OLIVER; HAZLER, 1992). Não seria, então, o caso de ajudá-los a confirmar que o outro a quem desprezam sente-se tão mal quanto eles se sentiriam na mesma situação?

Quanto à vítima, restam certezas de que, com frequência, seu pior inimigo é ela própria (AVILÉS, 2013), porque, como vimos, seus pensamentos e sentimentos se relacionam a certa autoculpabilização pelo que vive com seus pares. Cabe a nós, educadores, ajudar a superar essa condição. Meninos e meninas vítimas de bullying precisam de espaços em que, independentemente de como sejam, o respeito esteja presente. Precisam que os ajudemos a se indignar pelas injustiças que são cometidas.

Nossos dados nos mostram o quanto ainda é preciso fazer por nossos alunos nas escolas, pois eles não são espectadores que aguardam pelas nossas ações. Eles devem ser atuantes porque podem decidir, podem escolher, podem restaurar a paz, mediados por professores que entendam do desenvolvimento humano e permitam a expressão do que sentem e o que pensam.

Os resultados a que chegamos cumprem com nosso objetivo que era encontrar possíveis relações entre desengajamentos morais, participação em situações de bullying e as representações que os sujeitos têm de si como uma forma de avaliação do problema que se instaura entre nós. A partir deles, acreditamos que outras pesquisas devam ser realizadas, visando compreender um fenômeno que nos alerta sobre a necessidade de que mais do que leis que punam, é preciso sensibilidade para criar ambientes em que o respeito seja elemento presente no cotidiano daqueles que precisam de nossa ajuda. Assim, a avaliação do fenômeno implica, veementemente, a necessidade de se repensar as políticas públicas brasileiras. 


\section{REFERÊNCIAS}

ALMEIDA, Ana; CORREIA, Isabel; MARINHO, Sylvie. Moral disengagement, normative beliefs of peer group, and attitudes regarding roles in bullying. Journal of School Violence, v. 9, n. 1, p. 23-36, 2010.

AVILÉS, José María. Diferencias de atribución causal en el bullying entre sus protagonistas. Electronic Journal of Research in Educational Psychology, v. 4, n. 2, p. 136-148, 2006

Bullying: guia para educadores. Campinas: Mercado de Letras, 2013.

AVILÉS, José María; ALONSO, María Natividad. Análisis de componentes identificativos de la violencia en el contexto escolar. Violencia, conflicto y maltrato. Itinerario de frontera. In: CONGRESSO NACIONAL DE PSICOLOGIA DA SAÚDE, 7., 2008, Actas... Porto: ISPA, 2008. p. 119-129.

BANDURA, Albert. Moral disengagement in the perpetration of inhumanities. Personality and Social Psychology Review, v. 3, p. 193-209, 1999.

Selective moral disengagement in the exercise of moral agency. Journal of Moral Education, v. 31, p. 101-119, 2002.

BANDURA, Albert et al. Sociocognitive self-regulatory mechanisms governing transgressive behavior. Journal of Personality and Social Psychology, v. 80, p. 125-135, 2001.

BANSEL, Peter et al. Bullies, bullying and power in the contexts of schooling. British Journal of Sociology of Education, v. 30, n. 1, p. 59-69, 2009.

BARIAUD, Françoise. Le développement des conceptions de soi. In: RODRIGUEZ-TOMÉ, Hector Julio; JACKSON, Sandy; BARIAUD, Françoise. (Org.). Regards actuels sur l'adolescence. Paris: PUF, 1997. p. 49-78.

BENTLEY, Karen M.; LI, Anita K. F. Bully and victim problems in elementary schools and students' beliefs about aggression. Canadian Journal of School Psychology, v. 11, p. 153-165, 1995.

BESAG, Valerie E. Bullying among girls: friends or foes? School Psychology International, v. 27, p. 535-551, 2006.

BOSWORTH, Kris; ESPELAGE, Dorothy L.; SIMON, Thomas R. Factors associated with bullying behavior in middle school students. Journal of Early Adolescence, v. 19, p. 341-362, 1999.

ESLEA, Mike et al. Friendship and loneliness among bullies and victims: data from seven countries. Aggressive Behavior, v. 30, p. 71-83, 2004.

FEKKES, Minne; PIJPERS, Frans I. M.; VERLOOVE-VANHORICK, S. Pauline. Bullying: who does what, when and where? Involvement of childrens, teachers and parents in bullying behavior. Health Education Research, v. 20, n. 1, p. 81-91, 2005.

FISHER, Helen L. et al. Bullying victimization and risk of self-harm in early adolescence: longitudinal cohort study. BMJ, v. 344, p. 2683, 2012. 
HOOVER, John H.; OLIVER, Ronald; HAZLER, Richard J. Bullying: perceptions of adolescent victims in the Midwestern USA. School Psychology International, v. 13, p. 516-525, 1992.

JANSEN, Pauline W. et al. Prevalence of bullying and victimization among children in early elementary school: do family and school neighborhood socioeconomic status matter? BMC Public Health, v. 12, p. 494-523, 2012.

KOHLBERG, Lawrence. Estádios morales y moralización. El enfoque cognitivo-evolutivo. In: TURIEL, Elliot; ENESCO, Ileana; LINAZA, Josetxu (Comp.). El mundo social en la mente infantil. Madrid: Alianza, 1989.

LAHELMA, Elina. Gendered conflicts in secondary school: fun or enactment of power? Gender and Education, v. 1, n. 3, p. 295-306, 2002.

MENESINI, Ersilia; CAMODECA, Marina. Vergonha e culpa como reguladores de comportamento: as relações com o bullying, vitimização e comportamento pró-social. Britsh Journal of Developmental Psychology, v. 26, p. 183-196, 2008.

MENESINI, Ersilia et al. Moral emotions and bullying: a cross-national comparison of differences between bullies, victims and outsiders. Aggressive Behavior, v. 29, p. 515-530, 2003.

NANSEL, Tonja R. et al. Bullying behaviors among U.S youth. Journal of the American Medical Association, v. 16, p. 2094-2100, 2001.

OBERMANN, Marie-Louise. Moral disengagement among bystanders to school bullying. Journal of School Violence, v. 10, n. 3, p. 239-257, 2011.

OLWEUS, Don. Bullying at school: what we know and what we can do. Blackwell: Oxford, 1993.

Bullying at school: basic facts and effects of a school based intervention program. Journal of Child Psychology and Psychiatry, v. 35, p. 1171-1190, 1994.

Bully/victim problems in school. Irish Journal of Psychology, v. 18, n. 2, p. 170-190, 1997.

. Norway. In: CATALANO, Richard et al. (Ed.). The nature of school bullying: a cross-national perspective. London: Routledge, 1999. p. 11-48.

ORTEGA, Rosario; DEL REY, Rosario; MORA-MERCHÁN, Joaquín A. Violencia entre escolares. Conceptos y etiquetas verbales que definen el fenómeno del maltrato entre iguales. Revista Interuniversitaria de Formación del Profesorado, n. 41, p. 95-113, 2001.

PERREN, Sonja; GUTZWILLER-HELFENFINGER, Eveline. Cyberbullying and traditional bullying in adolescence: differential roles of moral disengagement, moral emotions, and moral values. European Journal of Developmental Psychology, v. 9, n. 2, p. 195-209, 2012.

PIAGET, Jean. O juízo moral na criança. São Paulo: Summus, 1932.

PORNARI, Chrisa D.; WOOD, Jane. Peer and cyber aggression in secondary school students: the role of moral disengagement, hostile attribution bias, and outcome expectancies. Aggressive behavior, v. 36, n. 2, p. 81-94, 2010. 
RINGROSE, Jessica; RENOLD, Emma. Normative cruelties and gender deviants: The performativity effects of bully discourses for girls and boys in school. British Educational Research Journal, v. 4, p. 1-24, 2009.

SÁNCHEZ, Virginia; ORTEGA, Rosario; MENESINI, Ersilia. La competencia emocional de agresores y víctimas de bullying. Anales de Psicología, v. 28, n. 1, 2012.

SAGONE, Elisabetta; LICATA, Laura. Relazione tra adattamento interpersonale, disimpegno morale, bullismo e comportamento prosociale: una ricerca nella scuola media. Giornale di Psicologia, v. 3, n. 3, p. 247-254, 2009 .

SCHWARTZ, David. Subtypes of victims and aggressors in children's peer groups. Journal of Abnormal Child Psychology, v. 28, p. 181-192, 2000.

SMITH, Adam. Teoria dos sentimentos morais. São Paulo: Martins Fontes, 1999.

SMITH, Peter K. Bullying: recent developments. Child and Adolescent Mental Health, v. 9, n. 3, p. 98-103, 2004.

SMITH, Peter K. et al. The nature of school bullying: a cross-national perspective. London: Routledge, 1999.

STEIN, Judith A.; DUKES, Richard L.; WARREN, Jasmin I. Adolescent male bullies, victims, and bully-victims: a comparison of psychosocial and behavioral characteristics. Journal of Pediatric Psychology, v. 32, n. 3, 2006.

THORNBERG, Robert; JUNGERT, Tomas. Bystander behavior in bullying situations: basic moral sensitivity, moral disengagement and defender self-efficacy. Journal of Adolescence, 2012.

TOGNETTA, Luciene Regina Paulino. Vencer o bullying escolar: o desafio de quem se responsabiliza por educar moralmente. In: TOGNETTA, Luciene Regina Paulino; VINHA, Telma Pileggi (Org.). É possível superar a violência na escola? São Paulo: Editora do Brasil, 2012. p. 100-115.

TOGNETTA, Luciene Regina Paulino; BOZZA, Thais Leite. Cyberbullying: um estudo sobre a incidência do desrespeito no ciberespaço e suas relações com as representações que adolescentes têm de si. Nuances, v. 23, n. 24, p. 164-180, 2012 .

TOGNETTA, Luciene Regina Paulino; LA TAILLE, Yves de. A formação da personalidade ética: representações de si e moral. Psicologia: Teoria e Pesquisa, v. 24, p. 181-188, 2008.

TOGNETTA, Luciene Regina Paulino; MARCOM, Guilherme Stecca; VINHA, Telma Pileggi. Os valores admirados por jovens de universidades públicas e particulares paulistas: serão valores éticos? In: ENCONTRO NACIONAL DE PROFESSORES DO PROEPRE, 25., 2012. Campinas. Anais... Campinas: Unicamp, 2012. p. 131-140, v. 2.

TOGNETTA, Luciene Regina Paulino; VINHA, Telma Pileggi. Construindo a autonomia moral na escola: os conflitos interpessoais e a aprendizagem dos valores. Revista Diálogo Educacional, v. 9, n. 28, p. 525-540, 2009. 
. Até quando? Bullying na escola que prega a inclusão social. Educação, Santa Maria, v. 35, n. 3, p. 449-464, 2010.

Reconhecimento de situações de bullying por gestores brasileiros e as intervenções proporcionadas. In: LINARES, José Jesús Gázquez et al. Investigación en el ámbito escolar: un acercamiento multidimensional a las variables psicológicas y educacionales. Almeria, Espanha: Editorial GEU, 2013. p. 227-232.

TURNER, Rhonda McConnell. Moral disengagement as a predictor of bullying and aggression: are there gender differences? Dissertation Abstracts International Section A: Humanities and Social Sciences, v. 69, n. 7-A, 2009.

WACHS, Sebastian. Moral disengagement and emotional and social difficulties in bullying and cyberbullying: differences by participant role. Emotional \& Behavioral Difficulties, v. 17, n. 3-4, p. 347-360, 2012.

WHITNEY, Irene; SMITH, Peter K. A survey of the nature and extent of bullying in junior/middle and secondary schools. Educational Researcher, v. 35, p. 3-25, 1993.

LUCIENE REGINA PAULINO TOGNETTA

Doutora em Psicologia Escolar pela Universidade de São Paulo (USP). Coordenadora do Gepem - Grupo de Estudos e Pesquisas em Educação Moral - da Universidade Estadual de Campinas (Unicamp) e Universidade Estadual Paulista "Júlio de Mesquita Filho" (Unesp), Brasil lrpaulino@uol.com.br

\section{PEDRO ROSÁRIO}

Professor doutor da Escola de Psicologia da Universidade do Minho (UMinho), Portugal. Coordenador do Guia - Grupo Universitário de Investigações em Autorregulação da UMinho prosario@psi.uminho.pt 